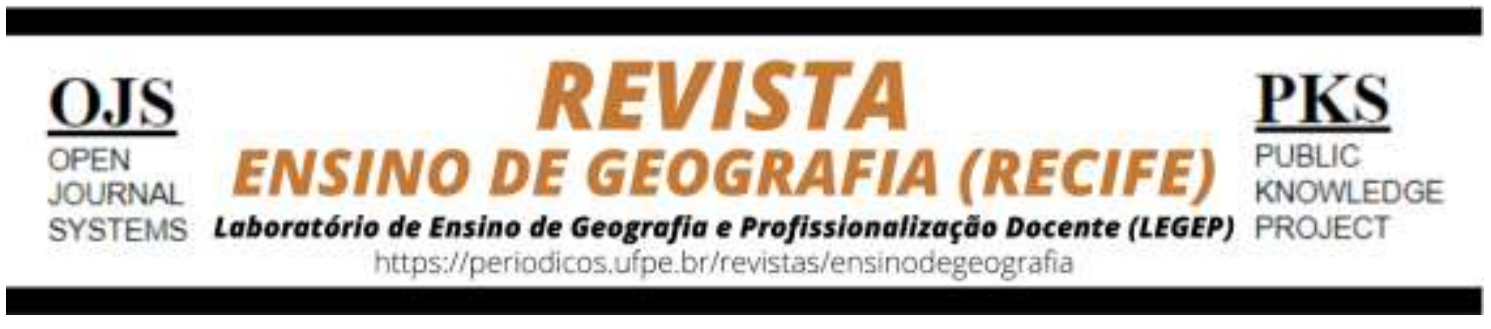

\title{
FORMAÇÃO DOCENTE EM GEOGRAFIA SOB A ÓTICA DO ESTADO DO CONHECIMENTO
}

\author{
Veroneide Maria de Oliveira ${ }^{1}$, Josélia Carvalho de Araújo² $^{2}$, Moacir Vieira da Silva ${ }^{3}$
}

\begin{abstract}
1 Mestranda no Programa de Pós-Graduação em Ensino (POSENSINO), da associação entre a Universidade do Estado do Rio Grande do Norte (UERN), Universidade Federal Rural do Semi-Árido (UFERSA) e o Instituto Federal de Educação, Ciência e Tecnologia do Rio Grande do Norte (IFRN). Email: veroneideoliveira@hotmail.com - ORCID iD: http://orcid.org/0000-0002-6757-3159

2 Professora Adjunta IV do Departamento de Geografia, Campus Central, Mossoró, da Universidade do Estado do Rio Grande do Norte.E-mail: joseliacarvalho@gmail.com - ORCID iD: http://orcid.org/00000001-7513-6621

${ }^{3}$ Professor permanente nas seguintes instituições de ensino: Escola Estadual Professor José de Freitas Nobre (SEEC - RN) e Escola Estadual Doutor Ewerton Dantas Cortes (SEEC - RN). E-mail: moacirvs31@hotmail.com - ORCID iD: http://orcid.org/0000-0003-1628-0935
\end{abstract}

Artigo recebido em 01/04/2020 e aceito em 07/04/2020

\begin{abstract}
RESUMO
Este artigo tem como foco o tema formação de professores. Objetiva conhecer o que vem sendo produzido no meio acadêmico sobre formação de professores de Geografia, nos últimos anos. Visando atingir esse objetivo, realizamos a análise de vinte trabalhos que versam sobre a temática, disponíveis no Catálogo de Teses e Dissertações da Coordenação de Aperfeiçoamento de Pessoal de Nível Superior (CAPES). O texto aqui apresentado se constitui, portanto, num estudo de caráter inventariante e descritivo. Aponta, como resultado da análise, que ainda persiste o distanciamento entre o conhecimento geográfico e a prática pedagógica no interior das disciplinas dos cursos de formação de professores, e de forma especial, em geografia - disciplina foco desse trabalho. Indica a necessidade de mudanças no trato com as disciplinas nos cursos de graduação, bem como uma significativa mudança de postura dos professores formadores dos futuros docentes nos cursos de graduação voltados para a licenciatura em geografia. Ainda evidencia a importância de políticas públicas, a exemplo do Programa Institucional de Bolsas de Iniciação à Docência (PIBID) para a formação do professor de Geografia.
\end{abstract}

Palavras-chave: Formação de professores. Ensino de Geografia. Produção do conhecimento.

\section{TEACHER FORMATION IN GEOGRAPHY FROM THE STATE OF KNOWLEDGE OPTICS}

\begin{abstract}
This article focuses on the theme teacher formation. It aims to know what has been produced in the academic environment on the formation of teachers of Geography, in recent years. In order to achieve this objective, we carried out the analysis of twenty papers on the subject, available in the Catalog of Theses and Dissertations of the Coordination for the Improvement of Higher Education Personnel (CAPES). The text presented here therefore constitutes a study of an inventive and descriptive character. It points out, as a result of the analysis, that the gap between geographic knowledge and pedagogical practice still exists within the disciplines of teacher formation courses, and in a special way, in geography - the subject of this work. It indicates the need for changes in the treatment of subjects in undergraduate courses, as well as a significant change in the attitude of teachers who train future teachers in undergraduate courses aimed at a degree in geography. It also highlights the importance of public policies, such as the Institutional Program for Teaching Initiation Scholarships (PIBID) for the training of Geography teachers.
\end{abstract}

Keywords: Teacher formation. Geography teaching. Knowledge production. 


\section{INTRODUÇÃO}

O professor é o promotor do processo de ensino, cujo sujeito central é o aluno. Por isso, é necessário uma atenção maior ao seu processo de formação profissional, principalmente, aos que se dedicam ao ensino básico, profissionais estes responsáveis por tão importante fase escolar. Para que este professor promova um ensino cujo sujeito central seja o aluno, requer uma sólida e diversificada formação na universidade, o que resultará numa significativa aprendizagem por parte do aluno, na geografia escolar.

No entanto, Pinheiro (2006) relata que estudos relacionados à formação de professores no Brasil apontam que os cursos de licenciatura têm apresentado vários problemas quanto à sua função na formação docente. Estes não têm atendido às necessidades de formação para todos os níveis do ensino. E no caso especifico da Geografia, as pesquisas mostram a desarticulação entre a formação acadêmica e a prática docente: "Os problemas residem na organização dos cursos, em sua desvalorização por alguns institutos e professores das disciplinas específicas e pedagógicas, além de sua pouca inserção na realidade" (PINHEIRO, 2006, p. 94).

Os problemas apontados anteriormente vão resultar no comprometimento da prática do futuro profissional, que chegará, no ensino básico, reproduzindo um modo de ensino da academicista, quase sempre baseado no conteúdo, o que contribuirá para a permanência do ensino de geografia de forma conteudista, mnemônica e sem nexo com a realidade do aluno. Essa prática vai ocasionar a perda de interesse do discente do ensino básico pela disciplina, prejudicando o processo de aprendizagem.

A geografia perde, assim, seu real significado que, segundo Callai (2003), é de fazer com que o aluno se perceba “[...] como participante do espaço que estuda, onde os fenômenos que ali ocorrem são resultados da vida e do trabalho dos homens e estão inseridos num processo de desenvolvimento [...]" (p. 58), em meio às constantes transformações do espaço geográfico atual.

Neste sentido, inquietos com esse quadro, nosso objetivo, neste artigo, é conhecer o que vem sendo produzido, no meio acadêmico, sobre a formação de professores de geografia. Por este motivo, empreendemos um Estado do Conhecimento sobre a referida temática. 
Segundo Romanowski e Ens (2006), o Estado do conhecimento é o estudo realizado a partir da sistematização de dados que abrangem uma área do conhecimento em apenas um setor das publicações sobre o tema estudado. Este caráter é o que o distingue dos estudos denominados Estado da Arte, que abrangem toda uma área de conhecimento, nos diferentes aspectos que geraram produções.

Os objetivos do Estado do Conhecimento "[...] favorecem compreender como se dá a produção do conhecimento em uma determinada área de conhecimento em teses de doutorado, dissertações de mestrado, artigos de periódicos e publicações [...]" (ROMANOWSKI; ENS, 2006, p. 39).

Estes estudos, como afirma Ferreira (2002), são definidos por seu caráter bibliográfico, e trazem em comum o desafio de "mapear" e discutir uma certa produção acadêmica em diferentes campos do conhecimento. Ainda, são reconhecidos pela realização de uma metodologia de caráter inventariante e descritiva da produção acadêmica e científica do tema investigado.

Dada a amplitude da produção científica sobre formação de professores em nível nacional, investigamos as produções disponíveis no Catálogo de Teses e Dissertações da Coordenação de Aperfeiçoamento de Pessoal de Nível Superior (CAPES). Escolhemos esta plataforma devido ao nosso interesse de conhecer o que vem sendo produzido na academia sobre formação de professores de geografia junto aos programas de pósgraduação stricto sensu, bem como dada a relevância e conceituação da Plataforma Capes, enquanto referência para o estudo e desenvolvimento das ciências.

A importância da investigação desenvolvida se justifica em função da necessidade de uma reflexão sobre o processo de formação docente e suas interferências no ensino básico, com o intuito de colaborar para a valorização da docência, a melhoria de seu processo formativo e para o processo de ensino e aprendizagem no nível básico de ensino.

O trabalho está estruturado da seguinte forma: na primeira parte trazemos, uma discussão sobre formação inicial do professor de Geografia, apoiando-nos em autores como Vesentini (2013), Callai (2003), Pinheiro (2006) e Castellar (2010), que estudam, dentre outras temáticas, a formação de professores de geografia e ensino de geografia; na segunda parte, apresentamos os resultados da investigação sobre a produção acadêmica relacionada à formação de professores de geografia junto a teses e dissertações disponíveis no Portal da Capes; e, por último, nossas considerações finais, ante os resultados encontrados em nossa investigação. 


\section{CONSIDERAÇÕES INICIAIS SOBRE A FORMAÇÃO DE PROFESSORES DE GEOGRAFIA}

No atual cenário de mudanças e discussões, o processo de formação de professores é algo que merece atenção. Formar aqueles que subsidiarão as bases para a construção do conhecimento formal na sociedade, faz-se mister, é algo primordial e requer cuidado, seriedade e bases sólidas por parte dos envolvidos nesta missão.

Principalmente, em meio às duras críticas e aos questionamentos que permeiam o sistema educacional e a própria prática docente no Brasil. Aliás, para a ciência geográfica aqui em questão, há algum tempo que esta vem sendo questionada sobre sua real contribuição e significância para o ensino. Sobre a disciplina de geografia, pairam acusações com relação a sua apresentação ainda nos moldes tradicionais da ciência, baseado em um modelo de ensino mnemônico, enciclopédico, sem nexo com a realidade do aluno.

No entanto, como afirma Vesentini (2013, p. 236), “O valor da escola e do professor é algo diretamente ligado à cultura e às prioridades de uma sociedade". E no Brasil, ainda segundo o autor, o que se presencia é uma tradição bacharelesca, que prioriza a formação do especialista em detrimento da formação docente, e que à exceção da docência universitária, essa formação ainda é vista como destinada àqueles que não têm competência para exercer outras atividades, seja na geografia ou em outras áreas (ibid).

A dicotomia entre a formação docente e a do bacharel tem bases na reforma educacional de 1971, que visava a ampliar o número de vagas no Ensino Básico, sobretudo na rede pública, exigindo maior número de professores e oferta de curso de formação, o que ampliou a oferta de cursos de curta duração em todo o território nacional, para alimentar o sistema de ensino (PINHEIRO, 2006).

O curso de Geografia era oferecido por apenas algumas universidades públicas, que formavam o professor e o bacharel. A separação em duas as modalidades, associado aos baixos salários e à precária condição de trabalho do professor neste período, promoveu a desvalorização da licenciatura em relação ao bacharelado. E essa dicotomia vem perpetuando-se até os dias atuais nas universidades, garantindo status de superioridade ao bacharelado, por formar o geógrafo perito/consultor/pesquisador, enquanto a licenciatura forma o professor, cuja função é "transmitir" os conteúdos resultantes dos estudos realizados pelos pesquisadores (PINHEIRO, 2006). 
Entretanto, essa visão estereotipada em relação à função do professor de geografia depende significativamente da formação à qual o docente tem acesso quando ainda está na universidade. Isto é, uma vez empreendida uma formação sólida na área de ensino de geografia, mostrando aos futuros docentes as vertentes e os caminhos do ensinar-aprender geografia, haverá profissionais qualificados para ensinar geografia, formando, inclusive, aqueles que um dia chegarão à universidade e se tornarão bacharéis em geografia. Observemos que o caminho se faz inverso. Ou seja, se o discurso dado é de que o professor de geografia ensina os conteúdos que o bacharel pesquisa, buscamos inverter o processo, apontando a função de excelência do professor de geografia na educação básica, contribuindo para que seus alunos possam chegar à universidade, e se formarem - ou não - enquanto bacharéis em geografia.

Essa inversão por nós proposta não objetiva arquitetar um conflito, acirrando ainda mais o debate entre a formação bacharelesca e a formação docente, nem tampouco ampliar o fosso entre as duas habilitações. Antes, visa, tão somente a apresentar o lado significativo do ensinar-aprender geografia, indicando a sua repercussão na vida do cidadão em formação na geografia escolar. Ademais, aponta uma senda de superação entre a Geografia dos Professores e a geografia dos Estados Maiores, discussão clássica presente na obra de Lacoste (1988): A geografia: isso serve, em primeiro lugar, para fazer a guerra.

Segundo Vesentini (2013), a estrutura de nossos cursos superiores, pela qual é enfatizada a especialização; a titulação, encarada como hierarquia ou relação de poder; e a nossa cultura autoritária, que relega a escolaridade e a qualificação das pessoas a segundo plano, contribuíram para engendrar ou reforçar inúmeros estereótipos na imagem da geografia escolar. Pois, "Na nossa tradição bacharelesca, o importante é ter um diploma e não, necessariamente, uma sólida formação escolar” (VESENTINI, 2013, p. 235).

Ao pesquisar sobre formação de professores no Brasil, Pinheiro (2006, p. 94) evidencia "[...] o distanciamento, na formação acadêmica, entre os conteúdos pedagógicos, conteúdos específicos e a realidade do trabalho docente, ocasionando, na prática dos professores, diversos problemas".

Os aspectos identificados e apontados por Pinheiro (2006), em seu estudo, impelenos a defender a necessidade de profundas alterações no que se refere ao trato da geografia, tanto no ensino básico quanto - e mais urgente - no ensino superior, posto que é nesse nível em que se formam os professores de geografia. 
A falta de comprometimento na formação do profissional da docência desta área do conhecimento contribui sobremaneira para a distorção da função dessa ciência e para seu descrédito junto à sociedade ao sistema de ensino. A geografia perde seu real sentido no ensino básico, o qual deve ser de

[...] preparar o aluno para: localizar, compreender e atuar no mundo complexo, problematizar a realidade, formular proposições, reconhecer as dinâmicas existentes no espaço geográfico, pensar e atuar criticamente em sua realidade tendo em vista a sua transformação (BRASIL, 2006, p. 43).

Ou ainda, como sugere Callai (2003, p. 58), a Geografia a ser estudada pelo aluno

\begin{abstract}
Não é aquela geografia que mostra um panorama da terra e do homem, fazendo uma catalogação enciclopédica e artificial, em que o espaço considerado e ensinado é fragmentado e parcial, e onde o aluno é um ser neutro, sem vida, sem cultura e sem história. O aluno deve estar dentro daquilo que está estudando e não fora, deslocado e ausente daquele espaço, como é a geografia que ainda é muito ensinada na escola: uma geografia que trata o homem como um fato a mais na paisagem, e não como um ser social e histórico.
\end{abstract}

E essa visão do aluno como centro do processo de ensino e aprendizagem é acessada se o sujeito aprendente no ensino superior - o futuro professor de geografia - é abrangido por uma sólida formação na área de ensino de geografia, tornando-o competente não só a ensinar, mas, acima de tudo, a saber ensinar; e mais ainda, a saber ensinar a aprender.

A partir da tomada de consciência do papel deste profissional na escola, espera-se mudanças em sua formação, uma vez que o trabalho docente de qualidade só ocorrerá diante de uma formação docente sólida, pautada em bases teórico-metodológicas e culturais. Uma formação precária prejudicará a ação docente na escola, e comprometerá a capacidade desse profissional de argumentar, interpretar e explicar o mundo, a realidade e as consequências que resultam dela, causando prejuízos ao processo de ensino e aprendizagem (CASTELLAR, 2010).

As prerrogativas para que se forme um bom profissional nos cursos de geografia são bem explicitadas por Vesentini (2013), que defende uma formação pluralista e autônoma, independente do campo de atuação profissional, seja na licenciatura ou nas mais diversas vertentes que o geógrafo possa atuar,

Portanto, a orientação para o curso de Geografia que pretenda formar bons profissionais (docentes ou não, tanto faz) é ter um adequado curso básico: que seja pluralista e contemple as diversas áreas e tendências da ciência geográfica; 


\begin{abstract}
que esteja voltado não para produzir especialistas e sim para desenvolver nos alunos a capacidade de "aprender a aprender", de pesquisar e observar, ler e refletir, de desconfiar de clichês ou estereótipos, de ter iniciativa e capacidade próprias. Com isso - ou seja, com um aluno que acompanhe os debates, os novos temas e as novas ideias, que é incentivado a observar e pensar por conta própria, que adquire um domínio mínimo de técnicas de pesquisa, de levantamento em bibliotecas ou arquivos etc. - está se formando um bom profissional que poderá lecionar ou se integrar a uma equipe que atue em outra atividade (VESENTINI, 2013, p. 239-240).
\end{abstract}

Corroborando do mesmo pensamento, porém em uma visão voltada para o campo de ensino, Castellar (2010) defende que a formação inicial docente deve estimular a sua autonomia, que por sua vez, estimula a mudança didático-pedagógica, o que vai incidir diretamente na formação cognitiva e ética do professor em um contexto sociocultural. Mas, para isso, a educação precisa ser entendida como um bem para formar cidadãos, com o Estado assumindo que a educação de qualidade é um direito do cidadão.

O processo de formação docente deve superar a dicotomia entre teoria e prática, integrando as bases teóricas com a prática cotidiana. E, dessa maneira, proporcionar ao futuro professor uma dimensão maior do significado dos saberes específicos e das práticas sociais, bem como agregar as experiências que evidenciam as diversas situações de conflitos escolares decorrentes dos diferentes valores e singularidades existentes nesse espaço (CASTELLAR, 2010).

O profissional da docência deve ser valorizado, e sua formação deve ter importância e ser discutida tanto quanto a formação dos demais profissionais, " [...] pois o professor se configura num dos principais atores da escola" (CASTELLAR, 2010, p. 40). Sua formação deve estar pautada em sua prática voltada para o ensino na escola básica, uma vez que os estudos apontam que é uma constante a falta de interação entre a universidade e a escola de nível básico.

\title{
AS PESQUISAS DISPONÍVEIS NO CATÁLOGO DE TESES E DISSERTAÇÕES DA CAPES SOBRE FORMAÇÃO DE PROFESSORES DE GEOGRAFIA
}

Posto que o trabalho em tela tem como objetivo conhecer o que vem sendo produzido no meio acadêmico sobre formação de professores de geografia, fez-se necessário realizar um estado do conhecimento acerca do tema, desenvolvendo um "mapeamento" que ocorreu junto ao site de catálogo de teses e dissertações da Capes.

A pesquisa começou a ser desenvolvida por meio de buscas na plataforma digital. $\mathrm{Na}$ investigação, utilizamos, a princípio, o descritor formação de professores de 
geografia, sem fazer uso de aspas, para termos uma noção da produção científica em torno do tema. Obtivemos como resultado um total de 1.146.270 trabalhos catalogados. No intuito de direcionar nossa pesquisa, passamos a fazer uso das aspas. Pela nova busca, agora com o descritor "formação de professores de geografia" (com aspas), obtivemos um resultado de 59 trabalhos, em três áreas do conhecimento: Geografia, Educação e Ensino. Dentro de duas grandes áreas do conhecimento: Ciências Humanas e Multidisciplinar. A partir daí, já poderíamos começar a delinear nosso estado do conhecimento. Destes trabalhos, 40 correspondiam a dissertações de mestrado e 19 a teses de doutorado.

No entanto, 30 trabalhos não estavam disponíveis para download, tornando-se inviáveis para análise, pois, para além da análise dos títulos, buscávamos avaliar os resumos, palavras chaves, introdução, metodologias e considerações finais, para identificarmos que se tratavam realmente da formação inicial de professores de geografia, que é o real objetivo da nossa pesquisa. Isto porque, como aponta Ferreira (2002), muitos trabalhos apresentam títulos difusos, que não relevam seu tema de fato. Restaram-nos, por fim, apenas 29 trabalhos considerados adequados à temática "formação de professores de geografia”.

Das 29 produções, 09 apresentaram temáticas destoantes da nossa pesquisa, restando assim, 20 trabalhos sobre "formação de professores de geografia”, os quais utilizamos para análise na elaboração deste ensaio. Destes, 07 correspondem a teses de doutorado e 13 a dissertações de mestrado.

Os trabalhos analisados estão compreendidos em um período de cinco anos de produção cientifica, do ano de 2013 a 2018. Embora não tivéssemos estabelecido a princípio um recorte temporal para a nossa pesquisa, este era o período de elaboração das produções disponíveis na Plataforma Capes, e as consideramos relevante e satisfatório ao nosso estudo. Para melhor demonstração e análise dos dados coletados e trabalhados, optamos por organizá-los em quadro (Quadro 1), no intuito de torná-los mais claros e apresentáveis no trabalho, facilitando a consulta e compreensão dos mesmos. 
Quadro 1 - Dissertações e teses sobre Formação de professores de Geografia

\begin{tabular}{|c|c|c|c|c|}
\hline ANO & AUTORES & TÍTULO & TIPO & INSTITUIÇÃO \\
\hline \multirow{7}{*}{2018} & $\begin{array}{l}\text { SIMAS, D. C. } \\
\text { V. de }\end{array}$ & $\begin{array}{l}\text { A formação de professores de geografia e o } \\
\text { Pibid pelo olhar dos professores supervisores } \\
\text { do subprojeto de geografia da UERJ-FFP }\end{array}$ & Dissertação & UERJ \\
\hline & $\begin{array}{l}\text { SANTOS, K. R. } \\
\text { dos. }\end{array}$ & $\begin{array}{l}\text { Políticas públicas na formação de professores } \\
\text { de Geografia: Análise dos efeitos do Programa } \\
\text { Institucional de Bolsa a Iniciação à Docência } \\
\text { nos anais do ENPEG } 2013\end{array}$ & Dissertação & UFPEL \\
\hline & $\begin{array}{l}\text { FRIGERIO, R. } \\
\text { C. }\end{array}$ & $\begin{array}{l}\text { Oficinas pedagógicas de geografia: costurando } \\
\text { narrativas de experiências da vida docente }\end{array}$ & Tese & UNICAMP \\
\hline & CORREIA, L. F. & $\begin{array}{c}\text { O Pibid/PUC-Rio no cenário das políticas } \\
\text { públicas educacionais: experiências de impacto } \\
\text { na formação de professores de Geografia para a } \\
\text { Educação Básica }\end{array}$ & Dissertação & PUC \\
\hline & $\begin{array}{l}\text { VERÍSSIMO, } \\
\text { A. dos S. }\end{array}$ & $\begin{array}{c}\text { A importância do Pibid para a formação } \\
\text { docente: a concepção dos alunos bolsistas do } \\
\text { curso de Geografia, da Universidade Federal de } \\
\text { Goiás - Regional Catalão }\end{array}$ & Dissertação & UFG \\
\hline & ROSA, B. M. da & $\begin{array}{l}\text { Formação de professores de Geografia no } \\
\text { entrecruzamento universidade e escola: PIBID } \\
\text { e Encontros sobre o Poder Escolar }\end{array}$ & Dissertação & UFPEL \\
\hline & $\begin{array}{l}\text { LIMA NETO, J. } \\
\text { C. de }\end{array}$ & $\begin{array}{l}\text { A Prática como componente curricular na } \\
\text { formação de professores de Geografia }\end{array}$ & Dissertação & UFG \\
\hline \multirow{4}{*}{2017} & $\begin{array}{l}\text { LARA, M. V. de } \\
\text { R. }\end{array}$ & $\begin{array}{l}\text { As disciplinas de prática de ensino como } \\
\text { componente curricular nos cursos de formação } \\
\text { de professores de geografia nas universidades } \\
\text { federais em Minas Gerais }\end{array}$ & Dissertação & UFSJ \\
\hline & LEITE, M. A. C. & $\begin{array}{l}\text { A Cartografia escolar como metodologia na } \\
\text { formação de professores de Geografia na } \\
\text { Universidade Estadual da Paraíba' }\end{array}$ & Dissertação & UFPB \\
\hline & $\begin{array}{l}\text { VALLERIUS, } \\
\text { D. M. }\end{array}$ & $\begin{array}{l}\text { A identidade profissional cidadã e o Estágio } \\
\text { Supervisionado de professores de Geografia }\end{array}$ & Tese & UFG \\
\hline & $\begin{array}{l}\text { SANTOS, R. A. } \\
\text { dos }\end{array}$ & $\begin{array}{l}\text { O professor de geografia e o conhecimento } \\
\text { docente: diálogos na construção do } \\
\text { conhecimento profissional }\end{array}$ & Tese & UFG \\
\hline \multirow{3}{*}{2016} & $\begin{array}{l}\text { WOITOWICZ, } \\
\text { L. }\end{array}$ & $\begin{array}{l}\text { A formação inicial de professores de geografia } \\
\text { no PIBID/UNIOESTE - Campus de Marechal } \\
\text { Candido Rondon - PR (2011-2015) }\end{array}$ & Dissertação & UNIOESTE \\
\hline & $\begin{array}{l}\text { CARVALHO, } \\
\text { L.S. }\end{array}$ & $\begin{array}{l}\text { Pibid de Geografia na Universidade Federal de } \\
\text { Goiás: proposta e experiências formativas Jataí } \\
\text { (GO) } 2016\end{array}$ & Dissertação & UFG \\
\hline & $\begin{array}{l}\text { CARVALHO, } \\
\text { M. A. N. de }\end{array}$ & $\begin{array}{l}\text { Representações sociais dos professores de } \\
\text { Geografia a respeito de sua formação inicial }\end{array}$ & Dissertação & UNISANTOS \\
\hline \multirow{3}{*}{2015} & $\begin{array}{l}\text { SANTOS, A. F. } \\
\quad \text { dos }\end{array}$ & $\begin{array}{l}\text { A formação do professor de geografia na } \\
\text { UFSC: concepção sobre o processo formativo }\end{array}$ & Dissertação & UFSC \\
\hline & $\begin{array}{l}\text { OLIVEIRA, M. } \\
\text { G. de }\end{array}$ & $\begin{array}{l}\text { A Prática como componente curricular na } \\
\text { perspectiva da formação inicial do professor de } \\
\text { Geografia para a Educação Básica }\end{array}$ & Dissertação & UNIOESTE \\
\hline & $\begin{array}{l}\text { SHIMIZU, R. de } \\
\text { C. G. }\end{array}$ & $\begin{array}{l}\text { Leitura Curricular da formação de professores } \\
\text { de Geografia: Brasil, Espanha e Portugal }\end{array}$ & Tese & UNESP \\
\hline \multirow{3}{*}{2013} & $\begin{array}{l}\text { BRAGA, R de } \\
\text { A. D. }\end{array}$ & $\begin{array}{c}\text { A Educação Ambiental na formação de } \\
\text { professores de Geografia em Araguaína (TO): } \\
\text { conexões e saberes }\end{array}$ & Tese & UFU \\
\hline & BUQUE, S. L. & $\begin{array}{c}\text { Conhecimentos docentes dos alunos da } \\
\text { licenciatura em geografia da Universidade } \\
\text { Pedagógica- Maputo }\end{array}$ & Tese & UFG \\
\hline & $\begin{array}{l}\text { SILVA, L. M. P. } \\
\text { e }\end{array}$ & $\begin{array}{l}\text { Culturas geográficas de alunos-jovens: uma } \\
\text { referência para a formação de professores de } \\
\text { Geografia }\end{array}$ & Tese & UFG \\
\hline
\end{tabular}

Fonte: Elaborado a partir do Banco de Teses e Dissertações da CAPES, no período de 2013 a 2018. Ano de obtenção dos dados 2019. 
Ao analisarmos os dados obtidos, percebemos que o Programa Institucional de Bolsas de Iniciação à Docência (PIBID) se constitui o aspecto mais abordado quanto à formação de professores de Geografia, estando presente em 07, dos 20 trabalhos analisados. O Pibid é uma política pública que tem como objetivo antecipar o vínculo entre os futuros mestres e as salas de aula da rede pública, fazendo uma articulação entre a educação superior (por meio das licenciaturas), a escola e os sistemas estaduais e municipais (BRASIL, 2018).

Há ainda, entre os trabalhos analisados, os estudos relacionados ao currículo, ao projeto político-pedagógico do curso, e à relação entre teoria e prática. Pesquisas voltadas para a prática de uma disciplina do curso de formação também apareceram de forma representativa na análise, por meio de disciplinas distintas, como a educação ambiental, a cartografia, a prática de ensino e o estágio.

De posse dos dados também pudemos categorizá-los, fazendo um comparativo da produção do conhecimento por região do país, em consonância às recomendações de Romanowski e Ens (2006). Em nosso estado do conhecimento, as regiões Sudeste e Centro-Oeste do Brasil foram as que mais se destacaram na realização de pesquisa sobre a formação de professores de geografia, com sete trabalhos cada. Logo em seguida, apareceu a região Sul, com cinco trabalhos; e a região Nordeste, com um trabalho apenas, realizado no ano de 2017. A região Norte não apareceu com publicações sobre a temática neste período. E no ano de 2014, não localizamos estudos que estivessem vinculados ao nosso objeto de estudo (Gráfico 1). Vale destacar que a diferença do número de trabalhos de pesquisa sobre "formação de professores de geografia" produzidos em cursos de mestrado e doutorado entre as regiões do Brasil se faz visível em função do desenvolvimento tardio da Pós-Graduação no Nordeste, em relação ao centro-sul do país.

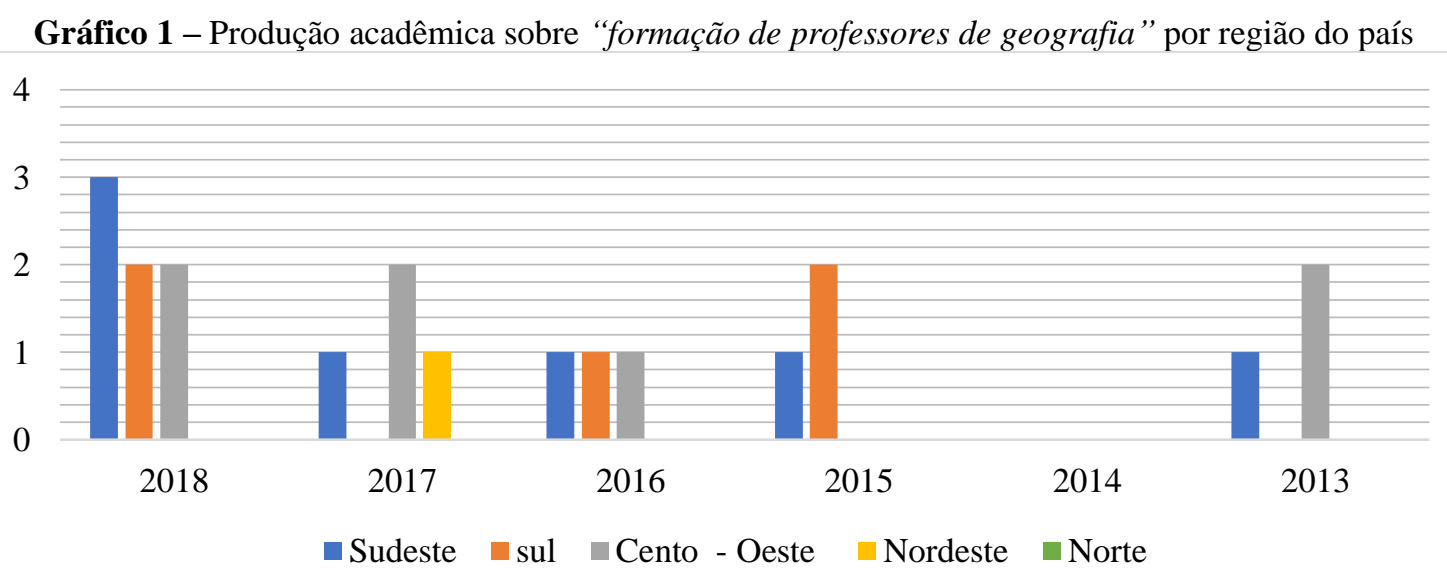

Fonte: Elaborado a partir do Banco de Teses e Dissertações da CAPES, 2019. 
Destacamos as produções da Universidade Federal de Goiás (UFG), que foi responsável pelas sete pesquisas na Região Centro-Oeste. Na região Sudeste, as produções ocorreram em universidades distintas, Universidade Estadual do Rio de Janeiro (UERJ), Universidade Estadual Paulista "Júlio de Mesquita Filho" (UNESP), Universidade Católica de Santos (UNISANTOS), Pontifícia Universidade Católica do Rio de Janeiro (PUC-RIO), Universidade Estadual de Campinas (UNICAMP), Universidade Federal de Uberlândia (UFU) e Universidade Federal de São João del-Rei (UFSJ). Cada instituição da região Sudeste, com um trabalho. Na região Sul do país, houve produção em três universidades. A Universidade Estadual do Oeste do Paraná (UNIOESTE), com duas produções; Universidade Federal de Santa Catarina (UFSC) e a Universidade Federal de Pelotas (UFPEL), com um trabalho cada. Na região Nordeste, encontramos penas um trabalho da Universidade Federal da Paraíba (UFPB). Estes dados podem ser visualizados no Quadro 2.

Quadro 2 - Instituições que produziram dissertações e teses sobre "formação de professores de

\begin{tabular}{|c|c|c|}
\hline REGIÃO & INSTITUIÇÃO & QUANTIDADE \\
\hline \multirow{7}{*}{ Sudeste } & UERJ & 1 \\
\hline & UNESP & 1 \\
\hline & UNISANTOS & 1 \\
\hline & PUC-RIO & 1 \\
\hline & UNICAMP & 1 \\
\hline & UFU & 1 \\
\hline & UFSJ & 1 \\
\hline \multirow{3}{*}{ Sul } & UNIOESTE & 2 \\
\hline & UFSC & 1 \\
\hline & UFPEL & 2 \\
\hline Cento-Oeste & UFG & 7 \\
\hline Nordeste & UFPB & 1 \\
\hline Norte & - & - \\
\hline
\end{tabular}

Fonte: Elaborado a partir do Banco de Teses e Dissertações da CAPES, 2019.

Segundo Santos (2018), “Assim como os objetivos permitem uma noção de temática, as palavras-chave se situam no mesmo sentido, ainda que mais genérico" (p. 51). Deste modo, resolvemos identificar as palavras-chave dos trabalhos. Ao observarmos o Quadro 3, é notório a predominância dos termos "formação de professores" e "ensino de geografia", que aparecem em oito dos vinte trabalhos. Em seguida, figuram "formação de professores de geografia" e "PIBID", seis vezes cada. A palavra-chave "formação de 
professores" chega a compor mais da metade das pesquisas, se levarmos em consideração que "formação de professores de geografia" compõe a mesma categoria, apenas identificando a área específica em estudo.

Outras palavras como: políticas públicas, licenciatura e formação inicial aparecem em menor proporção. Embora, presentes em menor quantidade nos trabalhos, são relacionadas ao estudo da questão, e nos dão uma compreensão do que as pesquisas buscaram abordar.

Quadro 3 - Palavras-chave das dissertações e teses sobre "formação de professores de geografia"

\begin{tabular}{|c|c|}
\hline PALAVRAS-CHAVE & QUANTIDADE \\
\hline Geografia & 5 \\
\hline Formação de professores & 8 \\
\hline Licenciatura & 1 \\
\hline Ensino de geografia & 8 \\
\hline Identidade & 1 \\
\hline Estágio supervisionado & 1 \\
\hline Cidadania & 1 \\
\hline Formação de professores de geografia & 6 \\
\hline Professor formador de geografia & 1 \\
\hline Conhecimentos específicos & 1 \\
\hline Conhecimentos pedagógicos & 1 \\
\hline Profissionalidade & 1 \\
\hline Educação superior & 1 \\
\hline Cultura geográfica & 1 \\
\hline Lugar & 1 \\
\hline Alunos-jovens & 1 \\
\hline Educação ambiental & 1 \\
\hline Interdisciplinaridade & 1 \\
\hline Formação continuada & 2 \\
\hline PIBID & 6 \\
\hline Políticas públicas educacionais & 1 \\
\hline Currículo & 1 \\
\hline Licenciatura em geografia & 1 \\
\hline Prática como componente curricular & 1 \\
\hline Cartografia escolar & 1 \\
\hline Escola básica & 1 \\
\hline Políticas públicas & 2 \\
\hline Educação básica & 2 \\
\hline Tendências didático-pedagógicas & 1 \\
\hline Disciplinas de práticas & 1 \\
\hline Projetos pedagógicos & 1 \\
\hline Diretrizes Curriculares Nacionais & 1 \\
\hline Grupos focais & 1 \\
\hline Licenciaturas em geografia & 1 \\
\hline Prática como Componente Curricular & 1 \\
\hline Formação inicial de professores & 1 \\
\hline Oficina pedagógica & 1 \\
\hline Formação docente & 1 \\
\hline Conhecimentos docentes & 1 \\
\hline Práticas formativas & 1 \\
\hline Formação inicial de professores de geografia & 1 \\
\hline Aprendizado do trabalho docente & 1 \\
\hline Formação inicial & 1 \\
\hline
\end{tabular}

Fonte: elaborado a partir do Banco de Teses e Dissertações da CAPES, 2019. 
No estudo, ainda buscamos investigar quais os métodos utilizados pelos pesquisadores para a coleta dos dados, por considerarmos que muito nos auxilia no entendimento do desenvolvimento das pesquisas e por nos dar um direcionamento dos principais métodos que estão sendo adotados pelos pesquisadores e quais outros ainda podem ser desenvolvidos em estudos posteriores. Destacaram-se os métodos de análise documental, aplicação de questionários, entrevistas, pesquisa bibliográfica e grupo focal, como sendo os mais utilizados. Outros métodos como: observação e narrativas aparecem de forma menos expressiva (Gráfico 2).

Gráfico 2 - Métodos utilizados pelos pesquisadores para a coleta dos dados na produção acadêmica sobre Formação de Professores de Geografia

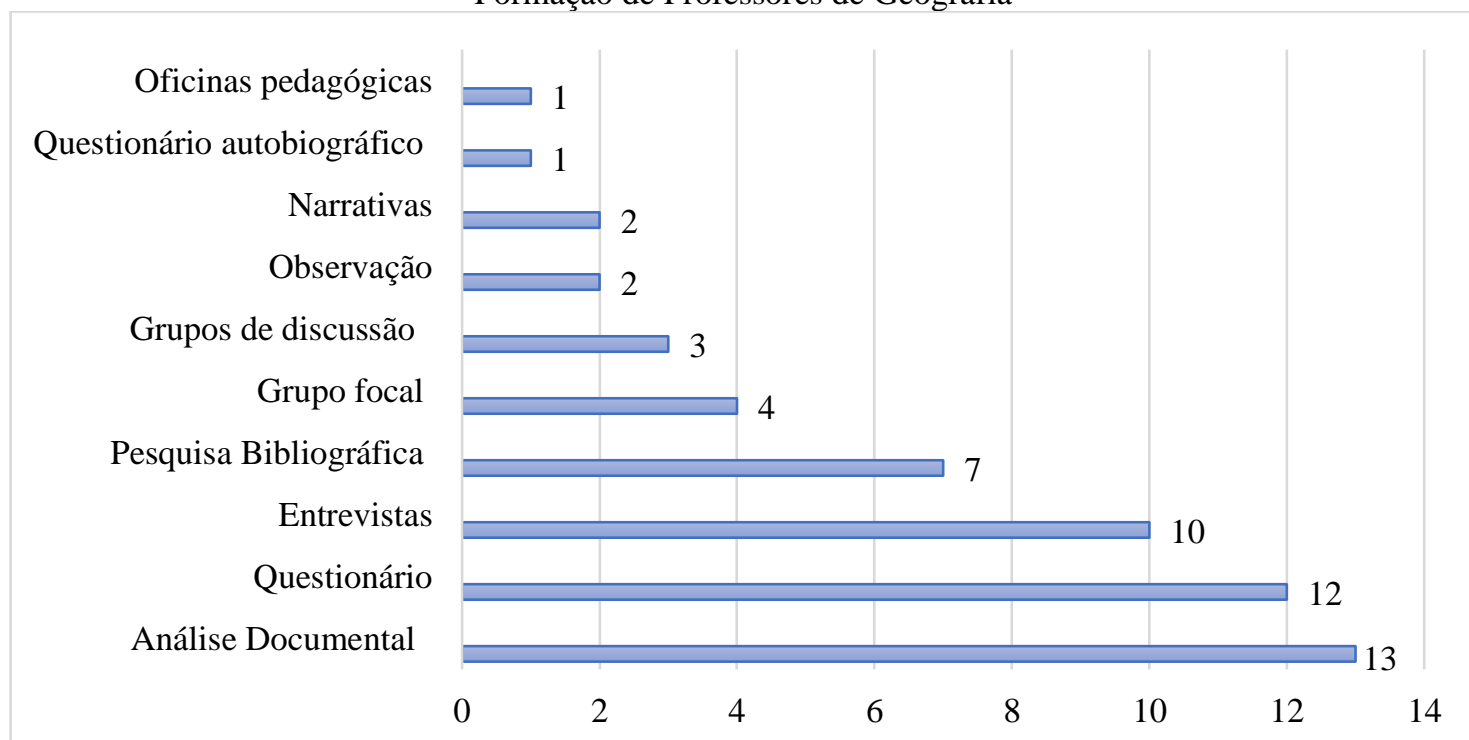

Fonte: Elaborado a partir do Banco de Teses e Dissertações da CAPES, 2019.

É valido lembrar que muitos trabalhos foram desenvolvidos com a utilização de mais de um método. Como por exemplo, o de Buque (2013), que se utilizou da pesquisa bibliográfica, pesquisa documental, questionário, observação de aulas, grupo focal e produção de narrativas em seu estudo com alunos de Licenciatura em Geografia. Ou ainda, Silva (2013), que afirmou recorrer a diversas técnicas de investigação, como a pesquisa bibliográfica, pesquisa documental, questionário, narrativas, grupos de discussão e entrevistas. Vallerius (2017), adotou como instrumentos metodológicos os questionários semiestruturados, as entrevistas individuais e os grupos focais.

No que se refere aos principais autores em cujos pensamentos se basearam os trabalhos analisados, muitos não fazem referência a esse aspecto no resumo, nem mesmo na parte de introdução e metodologia. As pesquisas que citam os principais autores em 
quem se baseiam os autores dos trabalhos analisados para a realização de suas pesquisas podem ser observados no Quadro 4, a seguir.

Quadro 4 - Principais autores que fundamentaram as dissertações e teses sobre "formação de professores de geografia"

Principais Autores Citados

CONTRERAS (2002), FREIRE (1996), GADOTTI (1999), GROSSSI (1993), LACERDA, (2017), LIBÂNEO (1998, 2004), MARQUES (2010), MIZUKAMI (2002), OLIVEIRA; PIRES (2017), PARO (2012), SAVIANI (1993), VAZQUEZ (1977), LARROSA (1994, 2011, 2013), NÓVOA, (1995, 2014), TARDIF (2002, 2012), TEDESCO (2009), MORIN (1999; 2001, 2000, 2002), PONTUSCHKA; PAGANELLI e CACETE (2009), CALLAI (2003, 2013, 2006, 2009, 2010), ABDALLA (2006; 2012, 2013A, 2013B), SAVIANI (2011), GARCÍA (2012), BENTO e OLIVEIRA (2012), BERTAZZO, SILVA (2014), BELO e JÚNIOR (2017), BOMFIM (2017), CARDOZO (2004), CAVALCANTI (1998, 2002, 2006, 2008, 2011, 2016, 2013, 2012), CONTI (1976), HARLEY (1991), LECIONE (2013), PIMENTA (1997, 1998, 1999, 2000, 2003), PONTUSCHKA (2001, 2007), RICHTER (2011), RABELO; BUENO (2015), SACRAMENTO (2015), STRAFORINI (2001), AMABILE (2017), AZEVEDO (1963, 1976, 2003), GATTI (2016), VASCONCELLOS (2000), MENDONÇA (2005), ROMANELLI (1986, 1999), ROSÁRIO; SILVA (2017), SOUZA (1991, 2001), VIEIRA (2008), LIMONTA (2013), CASTROGIOVANNI et. al. (2011), SOUZA (2009), SAMPAIO (2006), PIMENTEL (2010), MARTINS (2010), CARLOS (2007A, 2007B), SANTOS (1996, 2002), MASSEY (1997, 2000, 2012), TUAN (1983), PINHEIRO (2005), CANDAU (1999), VESENTINI (1987, 2002), SHULMAN (1986, 1987), GROSSMAN (1989, 1990), SACRISTAN (1998).

Fonte: Elaborado a partir do Banco de Teses e Dissertações da CAPES, 2019.

Dentre os autores que se dedicam especificamente ao tema "formação de professores de geografia” destacam-se: Pontuschka, Paganelli e Cacete; Cavalcanti e Callai; como apontado por Carvalho (2016). Ainda pontuaríamos Vesentini, Pinheiro e Castrogiovanni.

Assim, o catálogo de teses e dissertações da CAPES constituiu-se uma fonte relevante e confiável para nossa pesquisa, ao nos proporcionar através do seu banco de dados uma amostra do que vem sendo produzido na academia sobre formação de professores em Geografia. Possibilitou-nos conhecer o que vem sendo elaborado nesse campo de estudo, as abordagens e métodos adotados, ainda suscitando-nos novos olhares para a investigação da temática.

\section{CONSIDERAÇÕES FINAIS}

Os estudos sobre "formação de professores de geografia" mostram uma desarticulação entre os conteúdos trabalhados nos cursos acadêmicos e a realidade a ser trabalhada no ensino básico. Mostram que os cursos de licenciatura em geografia, na maioria das vezes, constituem-se em cursos de bacharelado "maquiados" com disciplinas 
pedagógicas que pouco contribuem no aperfeiçoamento da prática docente para o nível básico de ensino.

Quanto aos trabalhos encontrados no catálogo de teses e dissertações da CAPES sobre a temática, eles nos revelaram que grande parte dessas pesquisas estavam voltadas para a política de formação de professores, mais especificamente, para o estudo do PIBID e seus impactos na formação docente, seguido de estudos sobre o desenvolvimento de algumas disciplinas no ensino superior, a exemplo do estágio supervisionado, a disciplina de prática de ensino e educação ambiental. Percebemos pouca atenção para o estudo da concepção do egresso sobre as implicações de sua formação docente em sua prática de ensino.

Identificamos que essas pesquisas estão mais localizadas nas regiões Sudeste e Centro-Oeste do país, sendo pouco representativas na região Nordeste, e não identificadas na região Norte. Isso nos mostra a necessidade do desenvolvimento de estudos sobre a realidade dos cursos de formação de professores de geografia em todas as regiões, e principalmente, nestas duas últimas.

Em suma, os trabalhos revelam velhos problemas no que se refere à formação do professor de geografia, como os relacionados à metodologia e ao distanciamento entre o conhecimento geográfico e a prática pedagógica no âmbito das disciplinas do curso de formação de professores. Apontam a necessidade de mudanças no trato das disciplinas no Programa Curricular dos cursos de graduação em geografia e quanto à mudança de postura dos professores formadores dos futuros docentes. Ainda evidenciam a importância de políticas públicas, a exemplo do PIBID, para a formação do professor de geografia.

\section{REFERÊNCIAS}

BRASIL. Ministério da Educação. Orientações Curriculares para o Ensino Médio: ciências humanas e suas tecnologias. Brasília-DF, 2006. Disponível em: http://portal.mec.gov.br/seb/arquivos/pdf/book_volume_03_internet.pdf. Acesso em: 20 nov. 2018.

BRASIL. Ministério da Educação. Pibid - Apresentação, 2018. Disponível em: http://portal.mec.gov.br/pibid. Acesso em 05 de jun. 2019.

BUQUE, Suzete Lourenço. Conhecimentos docentes dos alunos da Licenciatura em Geografia da Universidade Pedagógica-Maputo. 2013. 257 f. Tese (Doutorado em Geografia) - Instituto de Estudos Socioambientais, Universidade Federal de Goiás, 2013. 
CALLAI, Helena Copetti. O ensino de Geografia: recortes espaciais para análise. p. 5763. In: CASTROGIOVANNI, Antonio Carlos. et al. (org.). Geografia em sala de aula: práticas e reflexões. 4. ed. Porto Alegre: UFRGS, 2003.

CARVALHO, Maria Angélica Nastri de. Representações Sociais dos professores de Geografia a respeito de sua formação inicial. 2016. 219 f. Dissertação (Mestrado em Educação) - Programa de Mestrado em Educação, Universidade Católica de Santos, Santos, 2016.

CASTELLAR, Sônia Maria Vanzella. Educação Geográfica: Formação e Didática. In: Eliana Marta Barbosa de Morais; Loçandra Borges de Moraes. (Org.). Formação de Professores: conteúdos e metodologias no ensino de Geografia. Goiânia: Editora Vieira, 2010, p. 39-58. Disponível em: nepeg.com/newnepeg/wp-content/uploads/2014/04/livroformação-de-professores-conteúdos-e-metodologias-no-ensino-de-geografia-2010.pdf. Acesso em 27 abr. 2017.

FERREIRA, Norma Sandra de Almeida. As pesquisas denominadas "estado da arte”. Educação \& Sociedade, São Paulo, ano 23, n. 79, p. 257-272, ago. 2002.

LACOSTE, Yves. A Geografia: isso serve, em primeiro lugar, para fazer a Guerra. Campinas: Papirus, 1988.

PINHEIRO, Antônio Carlos. Dilemas da formação do professor de Geografia no ensino superior. In: CAVALCANTI, Lana de Souza. Formação de professores: concepções e práticas em Geografia. Goiânia: Vieira, 2006.

ROMANOWSKI, Joana Paulin; ENS, Romilda Teodora. As pesquisas denominadas do tipo "estado da arte" em educação. Diálogo Educ., Curitiba, v. 6, n.19, p.37-50, set./dez. 2006.

SANTOS, Kainan Rodrigues. Políticas públicas na formação de professores de Geografia: Análise dos efeitos do Programa Institucional de Bolsa a Iniciação à Docência nos anais do ENPEG 2013. 2018. 70f. Dissertação (Mestrado em Geografia) - Instituto de Ciências humanas, Universidade Federal de Pelotas, Pelotas, 2018.

SILVA, Lucineide Mendes Pires e. Culturas Geográficas de alunos-jovens: uma referência para a formação de professores de Geografia, 2013. $276 \mathrm{f}$. Tese (Doutorado em Geografia) - Instituto de Estudos Socioambientais, Universidade Federal de Goiás, Goiânia, 2013.

VALLERIUS, Daniel Mallmann. A identidade profissional cidadã e o estágio supervisionado de professores de geografia. 2017. $204 \mathrm{f}$. Tese (Doutorado em Geografia) - Instituto de Estudos Socioambientais, Universidade Federal de Goiás, Goiânia, 2017.

VESENTINI, José Willian. A formação do professor de Geografia - Algumas reflexões. p. 235-240. In: PONTUSCHKA, Nídia Nacib; OLIVEIRA, Ariovaldo Umbelino (orgs.). Geografia em perspectiva: ensino e pesquisa. 4. ed. São Paulo: Contexto, 2013. 